\title{
A IncRNA-regulated gene expression system with rapid induction kinetics in the fission yeast Schizosaccharomyces pombe
}

\author{
ANGAD GARG \\ Molecular Biology Program, Sloan-Kettering Institute, New York, New York 10065, USA
}

\begin{abstract}
The fission yeast Schizosaccharomyces pombe is an excellent model organism for the study of eukaryotic cellular physiology. The organism is genetically tractable and several tools to study the functions of individual genes are available. One such tool is regulatable gene expression and overproduction of proteins. Limitations of currently available overexpression systems include delay in expression after induction, narrow dynamic range, and system-wide changes due to induction conditions. Here I describe a new long noncoding RNA (IncRNA)-regulated, thiamine-inducible expression system that integrates IncRNA-based transcriptional interference at the fission yeast tgp1 promoter with the fast repression kinetics of the thiamine-repressible nmt1 promoter. This hybrid system has rapid induction kinetics, broad dynamic range, and tunable expression via thiamine concentration. The IncRNA-regulated thiamine-inducible system will be advantageous for the study of individual genes and for potential applications in the production of heterologous proteins in fission yeast.
\end{abstract}

Keywords: regulated expression; thiamine-induced; IncRNA-regulation; rapid induction; tunable expression

\section{INTRODUCTION}

Fission yeast Schizosaccharomyces pombe is an excellent model system for the study of eukaryotic cell biology (Hoffman et al. 2015; Hayles and Nurse 2018). Fission yeast is also an appealing host for the production of heterologous eukaryotic proteins (Celik and Calik 2012). Regulatable gene expression systems are a major tool in understanding the function of individual genes and their products. Rapid induction kinetics, reproducible and titratable induction levels, and low reagent costs are advantageous features of expression systems for use in basic research and for industrial-scale protein production. Currently, the thiamine-repressible nmt1 (no message in thiamine) gene promoter is the most widely used regulatable gene expression system in fission yeast (Maundrell 1990; Basi et al. 1993; Forsburg 1993). Upon addition of thiamine, the nmt 1 transcript level declines after $1 \mathrm{~h}$ and is undetectable by $3 \mathrm{~h}$. When cells are transferred from thiamine-replete to thiamine-free medium, the expression of nmt1 mRNA is de-repressed after 14-16 h (Maundrell 1990). The nmt1 promoter system has been adapted to overexpress genes placed under its control on an extrachromosomal circular DNA (Basi et al. 1993; Forsburg

Corresponding author: garga1@mskcc.org

Article is online at http://www.rnajournal.org/cgi/doi/10.1261/rna. 076000.120 .
1993). Despite its popularity, the nmt1 system has the following limitations: (i) It takes 14-20 h to induce gene expression; (ii) it requires harvesting cells grown in medium with thiamine, conducting extensive washes and resuspending in thiamine-free medium, making it cumbersome for large cultures; and (iii) it has high basal expression in the repressed state when placed on a high-copy plasmid.

Several other regulatable fission yeast expression systems have been developed, variously entailing glucose depletion (fbp1 or inv1 promoter) (Hoffman and Winston 1989; lacovoni et al. 1999), ethanol induction (gld1 promoter) (Matsuzawa et al. 2013), heat-shock induction (hsp16 promoter) (Fujita et al. 2006), copper-based regulation (ctr4 promoter) (Bellemare et al. 2001), tetracycline-induction (tetracycline-regulatable cauliflower mosaic virus 35 S promoter) (Faryar and Gatz 1992; Forsburg 1993), uracil-based regulation (urg1 promoter) (Watt et al. 2008; Watson et al. 2011), estradiol-regulated induction (Ohira et al. 2017), and pheromone induction (sxa2/rep1 promoters) (Hennig et al. 2018). Many of these methods have limitations such as narrow dynamic range (e.g., tetracycline-

(C) 2020 Garg This article is distributed exclusively by the RNA Society for the first 12 months after the full-issue publication date (see http:// rnajournal.cshlp.org/site/misc/terms.xhtml). After 12 months, it is available under a Creative Commons License (Attribution-NonCommercial 4.0 International), as described at http://creativecommons.org/ licenses/by-nc/4.0/. 
induction); strain construction (uracil-based regulation); self-limiting gene expression (inv1 promoter); inductionbased growth arrest (pheromone induction); or eduction of stress and/or system-wide transcriptional changes (e.g., heat-shock induction, copper chelation, glucose depletion, and ethanol induction) (Chen et al. 2003; Rustici et al. 2007; Vassiliadis et al. 2019). To circumvent the limitations posed by current expression systems, I combined the properties of the thiamine-based nmt 1 promoter repression and regulation of the phosphate homeostasis gene tgp1 via upstream long noncoding RNA (IncRNA) transcription to build a vector with rapid and reliable kinetics of gene induction.

Fission yeast phosphate homeostasis is achieved by transcriptional control of the $\mathrm{PHO}$ regulon comprising three genes-pho1, pho84, and tgp1-encoding proteins involved in extracellular phosphate acquisition. Pho1 is a cell surface acid phosphatase, Pho84 is an inorganic phosphate transporter, and Tgp1 is a glycerophosphate transporter (Carter-O'Connell et al. 2012). The expression of these genes is dependent on Pho7, a member of the $\mathrm{Zn}_{2} \mathrm{Cys}_{6}$ family of transcription factors (Carter-O'Connell et al. 2012; Schwer et al. 2017; Garg et al. 2018a, 2019). In phosphate-rich conditions, the expression of each of these genes is repressed by the transcription of a $5^{\prime}$ adjacent cis-acting IncRNA: prt for pho1, prt2 for pho84, and nc-tgp1 for tgp1 (Lee et al. 2013; Ard et al. 2014; Shah et al. 2014; Schwer et al. 2015; Chatterjee et al. 2016; Garg et al. 2018b; Sanchez et al. 2018). The model of repression is that RNA polymerase II transcribing the IncRNA traverses the promoter of the downstream $\mathrm{PHO}$ gene, thereby ejecting Pho7 from the mRNA promoter and interfering with $\mathrm{PHO}$ gene expression (Chatterjee et al. 2016; Schwer et al. 2017; Sanchez et al. 2018). The current view of induction in phosphate-starved conditions hypothesizes that transcriptional shut-off of the IncRNA relieves transcriptional interference and thus de-represses the downstream phosphate homeostasis gene.

In this study, I describe a regulatable expression vector wherein the nmt1 promoter controls the synthesis of the IncRNA nc-tgp1 upstream of the tgp1 promoter, which in turn directs the transcription of a gene of interest. The addition of thiamine quickly halts synthesis of the nc-tgp1 IncRNA, thereby de-repressing the gene of interest. I further describe the tunability of this vector by titration of thiamine concentration as well as an alternative vector that affords a lower target gene expression level.

\section{RESULTS}

\section{IncRNA-regulated thiamine-inducible expression system}

Of the three phosphate homeostasis genes, tgp1 is the most tightly repressed in phosphate-rich conditions
(Marguerat et al. 2012). Repression occurs via transcriptional interference with the tgp 1 promoter by synthesis in cis of an upstream adjacent nc-tgp1 IncRNA (Ard et al. 2014; Sanchez et al. 2018). I used this property of the nctgp1-tgp1 gene cassette to engineer a regulatable promoter system on a plasmid.

The design involves placement of the nmt1 promoter upstream of the nc-tgp1 IncRNA transcription start site (TSS), which confers thiamine-based control of nc-tgp1 IncRNA expression (Figs. 1, 2A). Thus, in the absence of thiamine, nc-tgp 1 is at peak expression, thereby repressing the downstream tgp1 promoter. The addition of thiamine represses IncRNA expression and that in turn derepresses the downstream tgp1 promoter (Fig. 2A). To increase the repressive effect of nc-tgp1 transcription, I introduced mutations in a cluster of DSR elements in the nc-tgp1 IncRNA that are binding sites for Mmi1 (Figs. 1, 2A; Harigaya et al. 2006; Chen et al. 2011; Yamashita et al. 2012; Kilchert et al. 2015; Sanchez et al. 2018). The DSR mutations enhance IncRNA repression of the tgp1 promoter (Sanchez et al. 2018). The IncRNA-regulated thiamine-inducible expression system will henceforth be called the PTIN system (thiamine inducible) and the base vector will be referred to as PTIN.

To assay the activity of this promoter system, I utilized pho1 as the reporter gene driven by the tgp 1 promoter (Fig. 2A). Cell surface-associated Pho1 activity is readily assayable colorimetrically via the conversion of $p$-nitrophenylphosphate to $p$-nitrophenol. The pho1 gene was cloned downstream from the tgp $15^{\prime}$ UTR in the pTIN vector with its native $3^{\prime}$ flanking DNA to yield the pTIN-pho1 plasmid (Fig. 2A). To test background acid phosphatase levels, a promoter-less PTIN-pho1 vector was constructed that lacked the DNA segment spanning the regulatory nmt1-promoter-nc-tgp1-tgp1 promoter region as well as the tgp1 $5^{\prime}$ UTR and only contained the pho1 ORF. These plasmids were introduced into a strain in which the chromosomal pho 1 and pho4 genes encoding the cell-surface acid phosphatases Pho1 and Pho4 were deleted. Plasmid-bearing pho1 $1 \Delta$ pho4 $\Delta$ cells were grown to mid-log phase in $\mathrm{Leu}^{-}$ PMG medium without thiamine and subsequently diluted and grown in $\mathrm{Leu}^{-} \mathrm{PMG}$ medium with or without $15 \mu \mathrm{M}$ thiamine. Pho1 acid phosphatase activity was measured by incubating dilutions of cells with $p$-nitrophenylphosphate and measuring its conversion to $p$-nitrophenol for $5 \mathrm{~min}$ at $30^{\circ} \mathrm{C}$. The amount of product formed (within the linear range of detection) was normalized to cell density and is plotted on the $y$-axis in Figure 2B. In Leu- PMG medium with or without thiamine, the cells containing promoterless pTIN-pho1 had very low acid phosphatase activity (Fig. 2B). Cells bearing the pTIN-pho1 plasmid had 3.5fold higher acid phosphatase activity in thiamine-free medium compared to the promoter-less pTIN-pho1 control. Inclusion of thiamine elicited a 58-fold increase in acid phosphatase activity (Fig. 2B). 


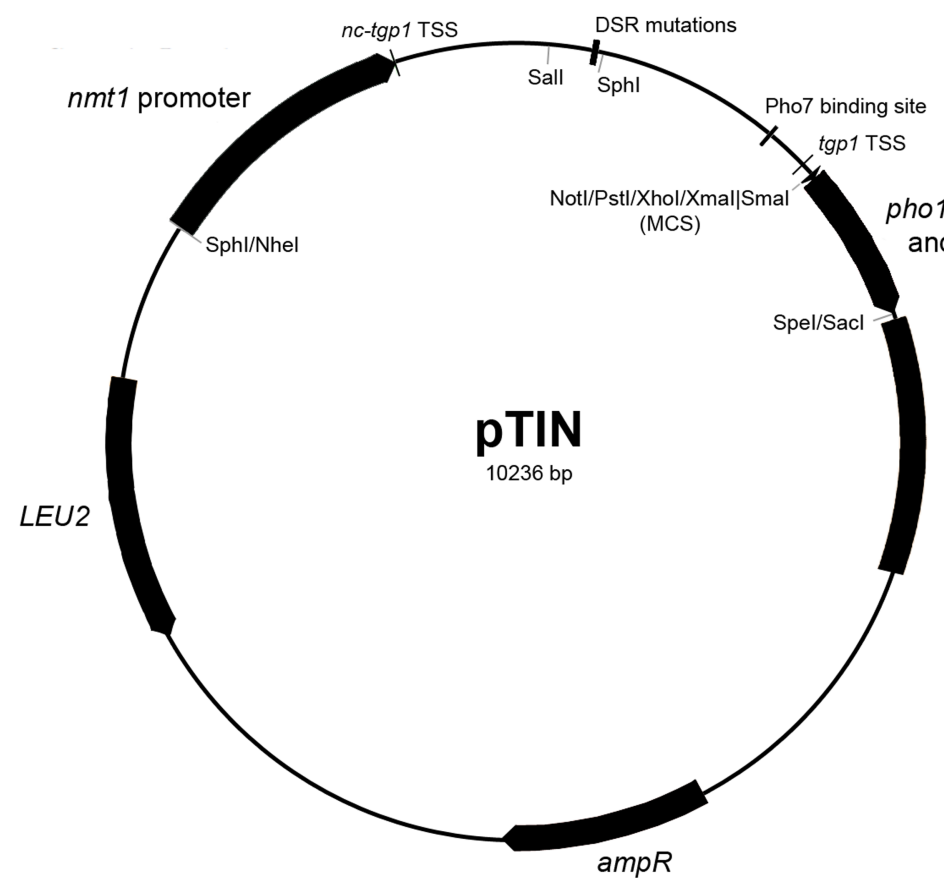

Pho7 binding site

WT: TCGGACATTCAA

mut: TCAGACATTCAA

DSR mutations

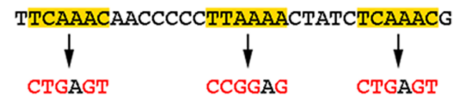

ARS1
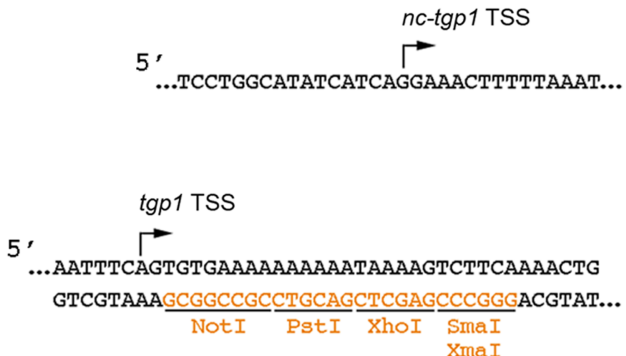

FIGURE 1. pTIN/pTIN7m plasmid map. Features of the pTIN/pTIN7m vector are depicted. The positions of the indicated restriction sites are shown. The DNA sequences of the WT or mutant (mut) Pho7 DNA binding site present in the pTIN or pTIN7m vector, respectively, and the base-specific changes for mutations in the DSR element cluster are indicated on the top right. The sequences of the following regions are shown at the bottom right- the nmt1 promoter fused to the nc-tgp1 IncRNA transcription start site (TSS), and the tgp1 5' UTR with the multiple cloning site polylinker (MCS), where the black bent arrow marks the initiating nucleotide of the IncRNA or the mRNA as indicated.

Cultures of pho1 $1 \Delta$ pho4 $\Delta$ cells bearing either the pTIN empty vector or PTIN-pho1 were serially diluted and spotted on Leu ${ }^{-}$PMG agar medium with or without $15 \mu \mathrm{M}$ thiamine. After $3 \mathrm{~d}$ of incubation at $30^{\circ} \mathrm{C}$, there was no difference in growth between cells harboring either the empty PTIN or the PTIN-pho1 plasmid, as gauged by colony size. Colony sizes were larger on thiamine-containing medium compared to medium lacking thiamine (Fig. 2C), consistent with the observation that thiamine is limiting for S. pombe growth (Maundrell 1990). The plates were subsequently processed for agarose overlay acid phosphatase assay. This assay follows the acid phosphatase-catalyzed conversion of $\alpha$-naphthyl phosphate to 1-naphthol, which in the presence of Fast Blue B salt forms a colored azo-dye, presenting as red coloration around the cells.

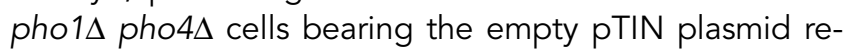
mained white in the presence or absence of thiamine, indicating low background signal (Fig. 2C). pho $1 \Delta$ pho $4 \Delta$ cells bearing PTIN-pho1 were similarly white when grown on medium lacking thiamine but were intensely red when grown on medium with thiamine (Fig. 2C).

\section{Kinetics of thiamine-induced gene expression}

I determined Pho1 acid phosphatase activity in pho1s pho $4 \Delta$ cells bearing the PTIN-pho1 plasmid as a function of time after addition of thiamine (Fig. 3A). Pho1 activity in- creased linearly between 1 and $7 \mathrm{~h}$ and continued to increase between 7 and $11 \mathrm{~h}$ at $58 \%$ of the initial rate. Extending the time course of thiamine induction to $23 \mathrm{~h}$ resulted in a 53-fold increase in Pho1 level over the uninduced state (Fig. 3A). To gauge the level of pho1 mRNA, I performed primer extension analysis using a pho 1-specific radiolabeled primer for reverse-transcription, in parallel with an actin gene-specific primer as a control. The pho1 mRNA was induced 25 -fold at 30 min after the addition of thiamine and attained a maximum level of 61 -fold by $1 \mathrm{~h}$ (Fig. 3B). The levels of pho1 mRNA remained at $\sim 60-$ fold higher than the uninduced state at all times assayed after $1 \mathrm{~h}$ (Fig. 3B; time points from 4 to $9 \mathrm{~h}$ not shown). The assessment of the kinetics of gene expression from the PTIN system show that the thiamine-dependent de-repression of the tgp 1 promoter allowed rapid transcriptional up-regulation, where peak levels of the pho1 mRNA were achieved by $1 \mathrm{~h}$. Continuous translation of the available pho1 mRNA resulted in the linear accumulation of Pho1 at the cell surface.

\section{Comparison to the thiamine-repressible nmt1 expression system}

To test the differences in the kinetics and absolute levels of induction of the PTIN system with the thiamine-repressed nmt1 expression system (Forsburg 1993), I measured acid 
A
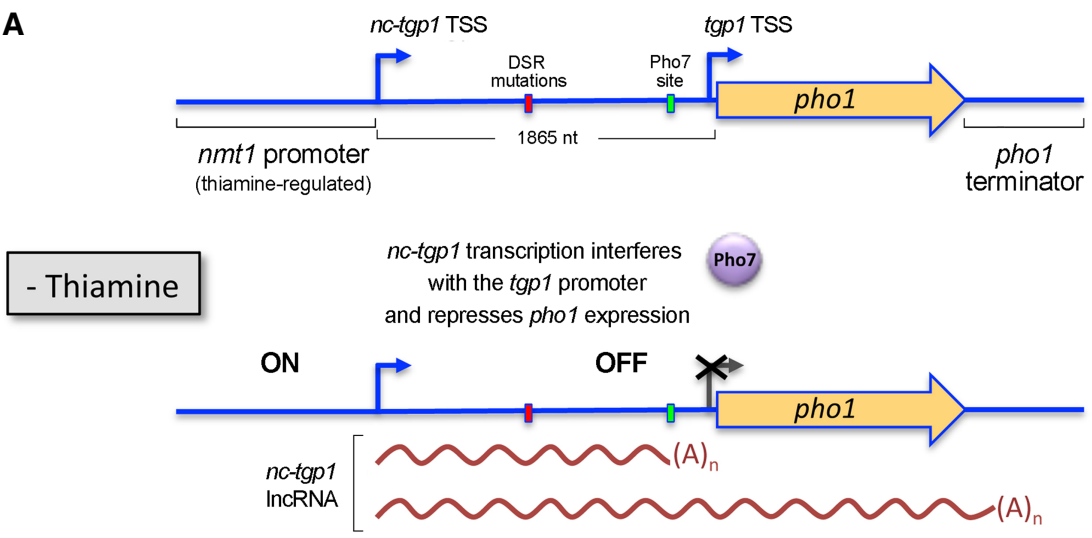

+ Thiamine Pho7 activates the

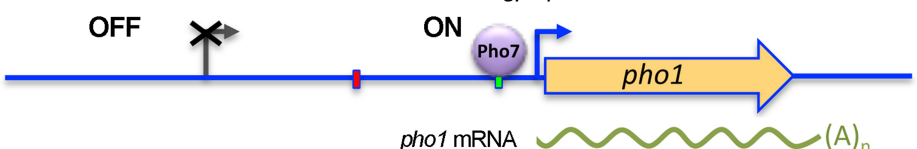

B

C

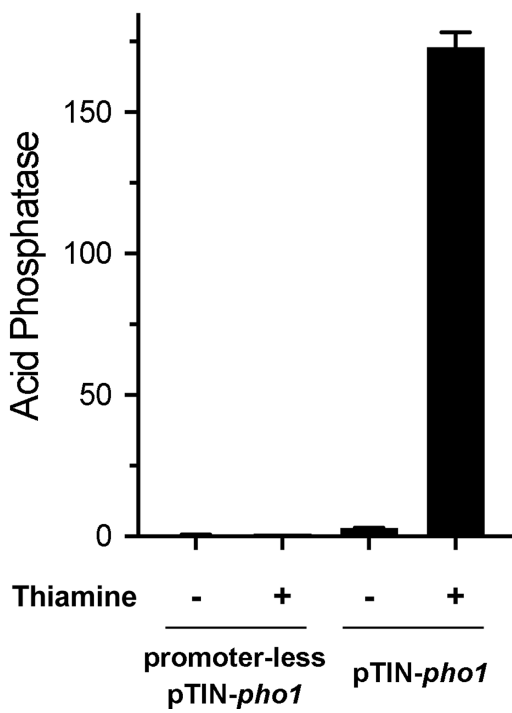

-Thiamine (OFF)

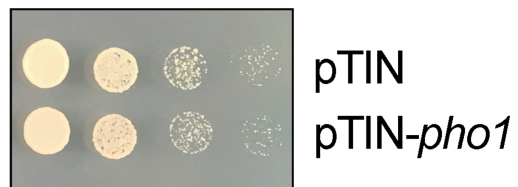

+Thiamine $(\mathrm{ON})$

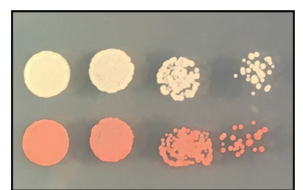

PTIN

pTIN-pho1

FIGURE 2. The pTIN system. (A) A schematic illustration of the IncRNA-regulated thiamine-inducible system using Pho1 acid phosphatase as a reporter (pTIN-pho1) is shown at the top. Transcription start sites are shown as bent arrows. The positions of the nc-tgp1 TSS, nc-tgp1 IncRNA DSR mutations (red box), tgp1 promoter Pho7 DNA binding site (green box), and tgp1 TSS are indicated. The distance between the nc-tgp1 TSS and the $-1 \mathrm{nt}$ relative to the tgp 1 translation start site is indicated by the bracket. The pho1 ORF is denoted by a gold horizontal arrow in the direction of mRNA synthesis. The mechanism of the IncRNA-regulated thiamine-inducible system is depicted below, where the thiamine-starved condition (-Thiamine) is the repressed state and thiamine-replete condition (+Thiamine) is the induced state for pho1 expression. The two predominant nc-

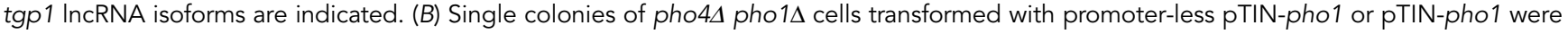
pooled $(\geq 20)$ and grown in Leu ${ }^{-}$PMG medium. Cells were diluted in Leu ${ }^{-}$PMG medium without or with $15 \mu \mathrm{M}$ thiamine, and acid phosphatase activity was measured after incubation at $30^{\circ} \mathrm{C}$ for $21 \mathrm{~h}$. The acid phosphatase activity is the average $\pm \mathrm{SEM}$ from three independent cultures. (C) A representative culture of pho4 $\Delta$ pho1 $\Delta$ cells bearing the PTIN empty vector or PTIN-pho1 were grown in Leu ${ }^{-}$PMG medium without thiamine at $30^{\circ} \mathrm{C}$. The cultures were adjusted to $A_{600}$ of 0.1 , and fivefold serial dilutions were spotted on Leu ${ }^{-} \mathrm{PMG}$ agar medium without or with $15 \mu \mathrm{M}$ thiamine and incubated at $30^{\circ} \mathrm{C}$ for $3 \mathrm{~d}$. The cells were overlaid with $1 \%$ agarose containing $0.015 \% \alpha$-naphthyl phosphate and $0.15 \%$ Fast Blue B Salt in $0.1 \mathrm{M}$ sodium acetate ( $\mathrm{pH}$ 4.2). The plates were photographed after incubation for $2 \mathrm{~min}$ at room temperature.

phosphatase activity of pho1 $1 \Delta$ pho4 $\Delta$ cells bearing the pTIN-pho1, pREP3X-pho1, pREP41X-pho1, or the pREP81X-pho1 plasmid as a function of time after induc- tion ( $\mathrm{pTIN}$ system: addition of thiamine; pREP-series: withdrawal of thiamine). In repressed conditions, the acid phosphatase activity of cells bearing PTIN-pho1 was 

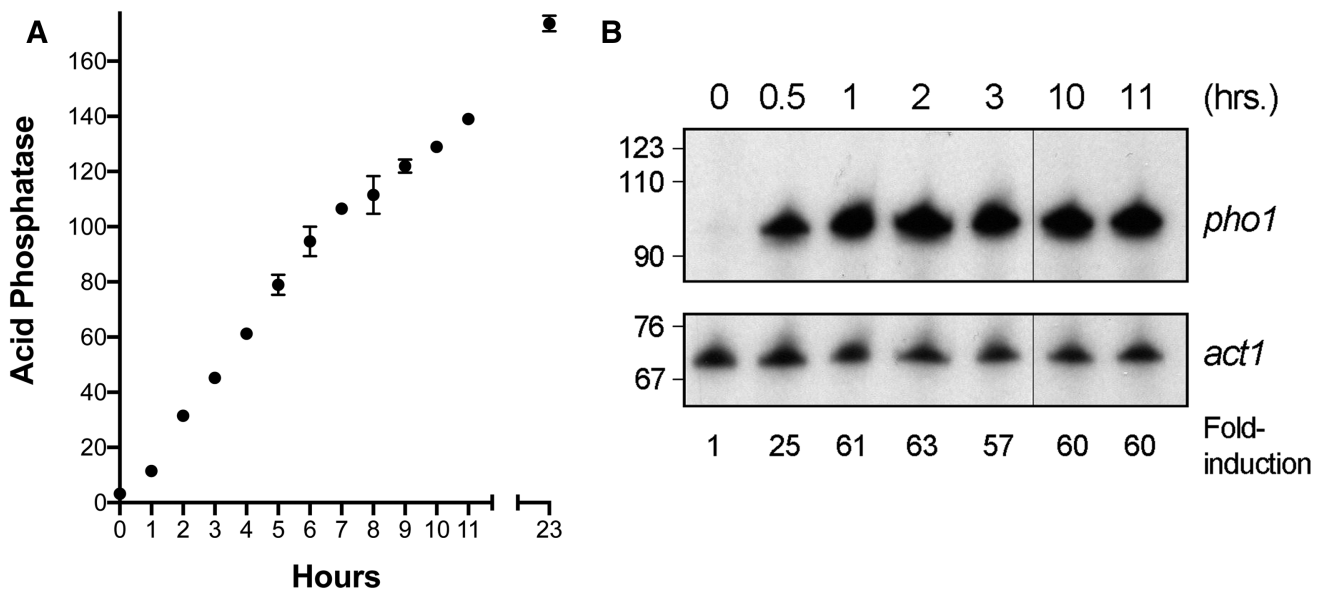

Hours

C

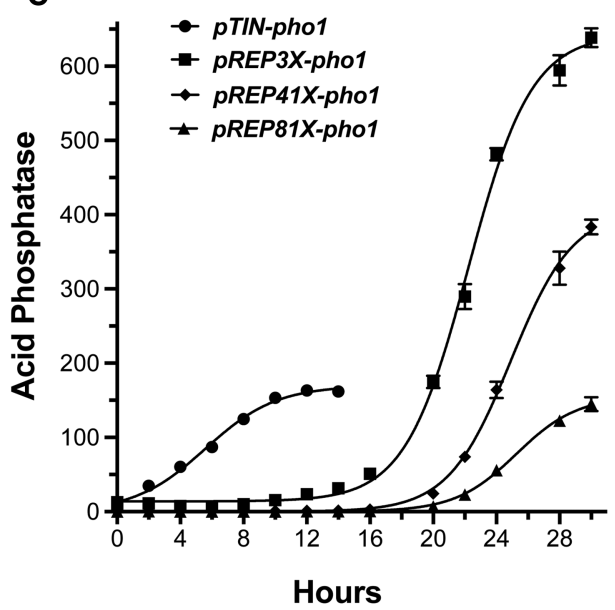

D

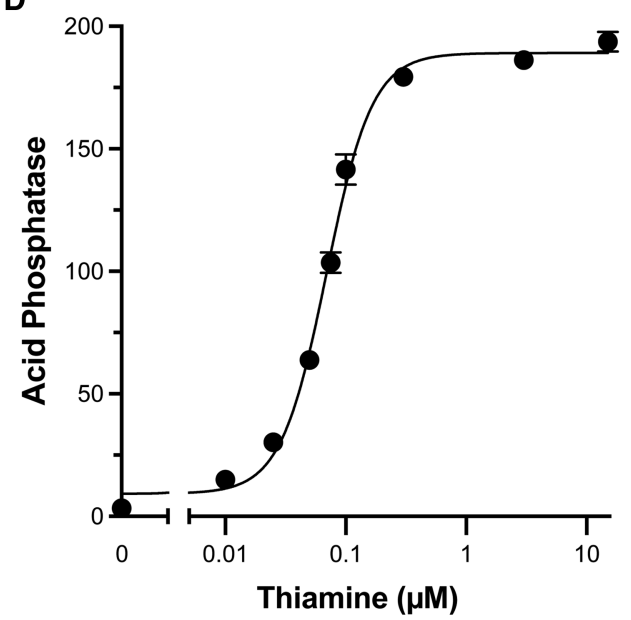

FIGURE 3. Kinetics of induction and titration of expression. (A) Single colonies of pho4 4 pho1 $1 \Delta$ cells transformed with the pTIN-pho1 plasmid were pooled $(\geq 20)$ and grown at $30^{\circ} \mathrm{C}$ in Leu ${ }^{-}$PMG without thiamine. Acid phosphatase activity was measured from an aliquot of the culture (time0 ) and the remaining culture was adjusted to $15 \mu \mathrm{M}$ thiamine. Acid phosphatase activity was measured at the indicated times after the addition of thiamine. Each data point is the average \pm SEM from three independent cultures. $(B) A$ representative culture of pho $4 \Delta$ pho $1 \Delta$ cells bearing the PTIN-pho1 plasmid was grown as described in Figure 3A, and aliquots were harvested before (time-0) or at the indicated times after the addition of thiamine. Total RNA prepared from harvested samples was analyzed by reverse transcription primer extension using a mixture of radiolabeled primers complementary to the pho1 (top panel) or the act1 (bottom panel) mRNAs. The reaction products were resolved by denaturing ureaPAGE and visualized by autoradiography. The images shown in the top and bottom panels are from a single exposure of one gel. For conciseness of the figure, the intervening lanes of the gel were cropped (represented by the thin line separating the 3- and 10-h samples). The positions and sizes (in nucleotides) of DNA markers are indicated on the left. Fold-induction reflects the ratio of the act1-normalized pho1 signal at the indicated time to time-0. (C) Single colonies of pho4 $\Delta$ pho1 $1 \Delta$ cells transformed with the indicated plasmids were pooled $(\geq 20)$, where the pTIN-pho1 or the $\operatorname{pREP}(3 \times ; 41 x ; 81 \times)$-pho1 bearing cells were grown in Leu ${ }^{-}$PMG medium lacking thiamine or containing $15 \mu \mathrm{M}$ thiamine, respectively. Pho1 expression was induced by adjusting thiamine concentration to $15 \mu \mathrm{M}$ for the pTIN-pho1 bearing cells or by pelleting cells, washing twice with water and resuspending in Leu ${ }^{-}$PMG medium lacking thiamine for the pREP-series-pho 1 bearing cells. Acid phosphatase activity was measured in repressed conditions (time- 0 ) and at the indicated times after induction. Each data point is the average \pm SEM from three independent cultures. The data were fit to a sigmoidal model (Boltzmann) in Graphpad Prism with a goodness of fit correlation coefficient of 0.99 for each induction curve. (D)

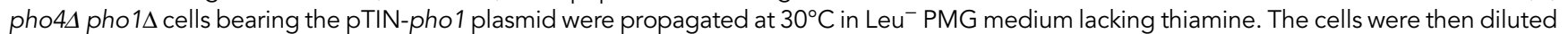
and grown for 20-23 $\mathrm{h}$ in Leu ${ }^{-}$PMG medium with the indicated thiamine concentration. The acid phosphatase activity is the average \pm SEM from three independent cultures. The data were fit to a dose-response model ( $E C_{50}$ shift) in Graphpad Prism with a goodness of fit correlation coefficient of 0.99 , Hill slope of 2.29 , and dose of half maximal response $\left(E_{50}\right)$ of $0.069 \pm 0.005 \mu \mathrm{M}$ thiamine.

fourfold lower than pREP3X-pho1 bearing cells, and fourfold or 15-fold higher than that of the pREP41X-pho1 or pREP81X-pho1 bearing cells, respectively (Fig. 3C). The PTIN-pho1 bearing cells induced Pho1 activity without a detectable lag period compared to the pREP3X-pho1,
pREP41X-pho1, or pREP81X-pho1 bearing cells, which induced Pho1 activity after a lag of 14, 16, or 20 h, respectively (Fig. 3C). The data were fit to the Boltzmann sigmoidal model which specified the following times for half maximal induced Pho1 activity-pTIN-pho1: 5.6 \pm 
0.4 h, pREP3X-pho1: $22.2 \pm 0.2$ h, pREP41X-pho1: $24.9 \pm$ $0.3 \mathrm{~h}$, pREP81X-pho1: $25.3 \pm 0.4 \mathrm{~h}$. The model-derived maximum induced acid phosphatase activity of the PTINpho1 bearing cells was fourfold lower, 2.5-fold lower or equivalent to the pREP3X-pho1, pREP41X-pho1, or pREP81X-pho1 bearing cells, respectively.

\section{Effects of thiamine concentration}

The levels of expression from the nmt1 promoter can be titrated by varying the thiamine concentration in the growth medium (Javerzat et al. 1996). To test the effects of thiamine concentration on the PTIN system, I propagated pho1s pho4s cells bearing the pTIN-pho1 plasmid in $\mathrm{Leu}^{-}$PMG medium either lacking thiamine or containing different concentrations of thiamine. Pho1 activity was induced by 59-fold for cells grown in Leu ${ }^{-}$PMG medium with $15 \mu \mathrm{M}$ thiamine compared to medium lacking thiamine. Cells grown in $\mathrm{Leu}^{-}$PMG medium with 0.01, $0.025,0.05,0.075,0.1,0.3$, and $3 \mu \mathrm{M}$ thiamine had Pho1 activities that were $8 \%, 16 \%, 33 \%, 54 \%, 73 \%, 93 \%$, and $96 \%$, respectively, of the level attained with $15 \mu \mathrm{M}$ thiamine (Fig. 3D). Fitting the data to a dose-response curve indicated that half-maximal induction was attained at $0.069 \pm 0.005 \mu \mathrm{M}$ thiamine and was saturated at $\geq 0.3 \mu \mathrm{M}$ thiamine. Thus, expression of the target protein can be titrated across a wide range by varying the thiamine concentration in the growth medium.

\section{Effects of Pho7 site mutation on the pTIN system}

The tgp 1 promoter has one binding site for the transcription factor Pho7 and retains $15 \%$ of its activity in the absence of Pho7 (Schwer et al. 2017). A single nucleotide change of the Pho7 site from 5'-TCGGACATTCAA to 5'TCAGACATTCAA severely weakens its interaction with the Pho7 DNA binding domain in vitro and reduces in vivo tgp 1 promoter activity to $20 \%$ of the wild-type (Garg et al. 2018a).

Here, I introduced this single-nucleotide mutation at the Pho7 site in the tgp 1 promoter of the PTIN plasmid, thereby generating a second-generation vector pTIN7m, into which I cloned the pho1 reporter gene (Fig. 4A). pho1s pho4s cells bearing the pTIN7m empty vector or pTIN7m-pho1 plasmids were grown in Leu ${ }^{-}$PMG medium without or with thiamine and assayed for acid phosphatase activity. As expected, there was negligible Pho1 acid phosphatase generated in cells bearing the pTIN7m vector (Fig. 4B). The key findings were as follows: (i) The uninduced level of Pho1 activity from pTIN7m-pho1 was 12fold lower than that derived from the pTIN-pho1 with an intact Pho7 site; (ii) addition of thiamine resulted in a 172-fold increase in Pho1 activity; and (iii) the level of thiamine induced Pho1 expression from pTIN7m-pho1 was $24 \%$ of that derived from the pTIN-pho1 (Fig. 4B, com-

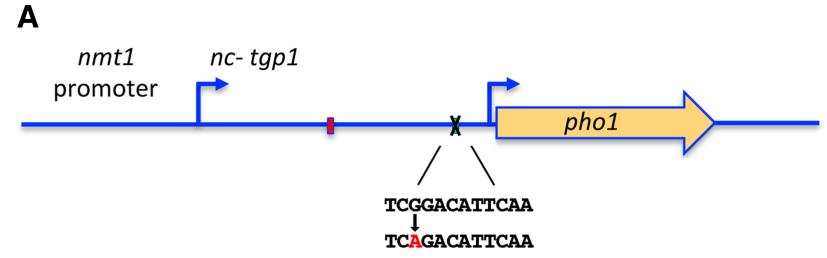

B

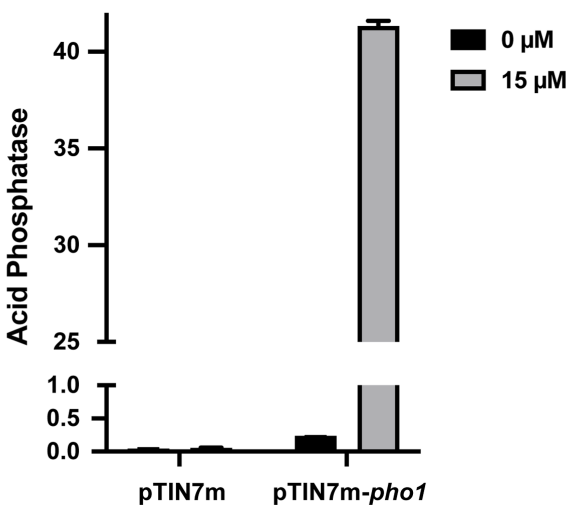

FIGURE 4. Effects of Pho7 site mutation on the pTIN system. (A) In the pTIN7m-pho1 plasmid, the IncRNA-regulated thiamine-inducible regulatory region with a mutated Pho7 binding site fused to the pho1 ORF is shown as a schematic. The regulatory region is described in Figure 2A with the following exception: the green box with a black cross represents a mutated Pho7 DNA binding site and the base-specific change is indicated. (B) Single colonies of pho4 $4 \Delta$ pho1 $\Delta$ cells transformed with pTIN7m or pTIN7m-pho1 were pooled $(\geq 20)$ and grown at $30^{\circ} \mathrm{C}$ in Leu ${ }^{-} \mathrm{PMG}$ medium. The cultures were diluted and grown for $22 \mathrm{~h}$ in Leu ${ }^{-}$PMG medium with the indicated thiamine concentration and acid phosphatase activity was measured. Each data point is the average \pm SEM of three independent cultures.

pared to Fig. 2B). These results show that the amplitude of the PTIN system can be dampened without adversely affecting the fold induction in response to thiamine.

\section{pTIN-based overexpression of the mitotic transcription factors Sak1 and Fkh2}

I exploited the PTIN system to overexpress the fission yeast transcription factors Sak1 and Fkh2 that regulate the mitotic (M) phase of the fission yeast cell cycle (Garg et al. 2015). Overexpression of Sak1 or Fkh2 by other methods leads to abnormal cell cycle phenotypes and growth inhibition (Buck et al. 2004; Vachon et al. 2013; Garg et al. 2015). Here I find that Sak1 or Fkh2 expression via the PTIN system prevented growth and that this was attributable to their overexpression, insofar as (i) the pTIN empty vector had no effect on growth; and (ii) growth inhibition was seen in the presence of thiamine when the IncRNA-regulated tgp1 promoter was on, but not in the absence of thiamine when the IncRNA-regulated tgp 1 promoter was off (Fig. 5A). Note that cells bearing pTIN-sak1 grew more slowly than cells with the pTIN empty vector as gauged by colony size (discussed below). 
A

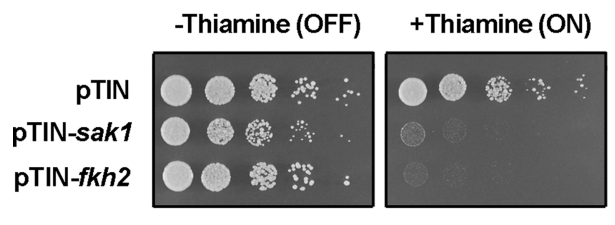

B
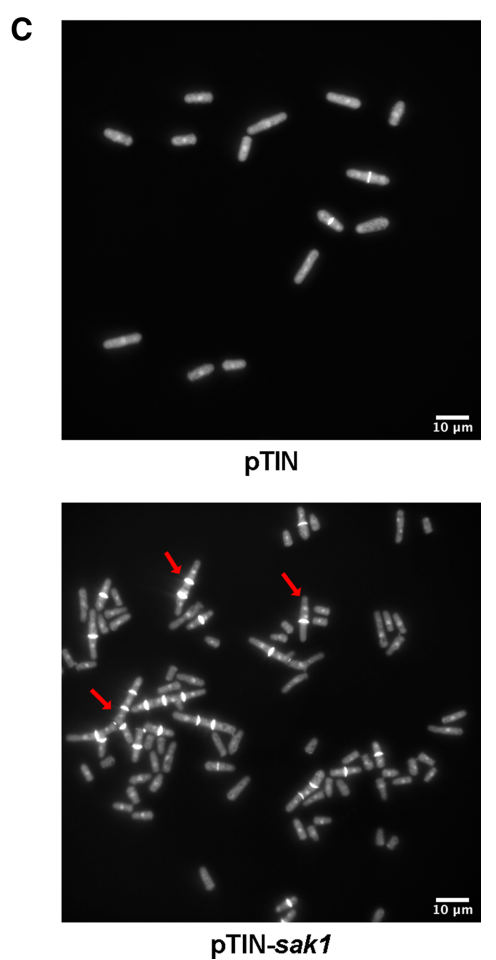

FIGURE 5. Overexpression of the mitotic transcription factors Sak1 and Fkh2. (A) Single transformants of WT cells bearing the pTIN, pTIN-sak1, or pTIN-fkh2 plasmids were propagated in Leu- PMG medium without thiamine. Serial dilutions of cells were spotted on Leu ${ }^{-}$PMG medium with or without $15 \mu \mathrm{M}$ thiamine and were incubated at $30^{\circ} \mathrm{C}$ for 3 or $4 \mathrm{~d}$, respectively. (B) A representative culture of WT cells bearing either the pTIN empty vector or PTIN-sak1 plasmid were grown at $30^{\circ} \mathrm{C}$ in Leu ${ }^{-}$PMG medium lacking thiamine. An aliquot of the cultures was fixed (time 0) and the remaining volume of cultures was adjusted to $15 \mu \mathrm{M}$ thiamine. The cultures were incubated at $30^{\circ} \mathrm{C}$ and an aliquot of each culture was fixed after $24 \mathrm{~h}$. Fixed samples were processed for DAPI and Calcofluor White staining and the proportion of septated cells was quantified by fluorescence microscopy. The total number of cells counted for each sample is indicated above the bar. The Z-test two tailed $P$-values comparing the proportion of total septated cells of pTIN and pTIN-sak1 samples are $0 \mathrm{~h}: 0.30 ; 24 \mathrm{~h}: 9.18 \times 10^{-24}$. (C) Fluorescence images (DAPI and Calcofluor) of cells bearing the indicated plasmids (described in Fig. 5B) under de-repressed (+thiamine) conditions at $24 \mathrm{~h}$. Red arrows indicate examples of cells with aberrant mitosis.

It has been shown that Sak1 overexpressed from the nmt1 promoter system advances mitosis leading to a higher septation index (proportion of cells with a single medial septum) and shorter cell lengths at septation (Garg et al. 2015). To observe phenotypes of overexpressing Sak1 from the pTIN system, cells bearing either the pTIN or pTIN-sak1 plasmid were visualized by fluorescent microscopy staining the nucleus with DAPI and the septum with Calcofluor in the uninduced state and at $24 \mathrm{~h}$ after thiamine induction (Fig. 5B,C). In noninducing conditions, pTIN-sak1 bearing cells had a septation index similar to the PTIN vector control (Fig. 5B), but had an average cell length at septation that was shorter by $1.28 \pm 0.40 \mu \mathrm{m}$ (two-tailed t-test $P$-value: 0.002). Thus the slower growth rate of the PTIN-sak1 bearing cells in the absence of thiamine may be attributable to some degree of mitotic advancement by basal Sak1 expression. Inducing Sak1 expression led to an increase in the septation index and abnormal septation (percentage of septated cells that had two or more septa, missegregated nuclei and/or were misshaped) (Fig. 5B,C). The septation index of con- trol cells bearing the pTIN empty vector was unaffected by thiamine (Fig. 5B,C). Thus, in accordance with prior observations, Sak1 overexpression-based increase in the septation index and abnormal septation indicated cell cycle defects.

\section{DISCUSSION}

The present study describes the design and implementation of a IncRNA-regulated thiamine-inducible expression system in the fission yeast Schizosaccharomyces pombe. This system has several advantages. Rapid kinetics allow peak target mRNA levels to accumulate by $1 \mathrm{~h}$ after induction (Fig. 3B) and makes it possible to follow the effects of overproducing a gene product within one generation time of the fission yeast life cycle. The target protein is translated continuously and accumulates progressively after the induced steady-state mRNA level is achieved (Fig. 3A,C). The PTIN system has a broad dynamic range, seen as a 60-fold transcriptional induction when fully de-repressed by the addition of thiamine (Figs. 2B, 3B). The level of 
protein expression can be tuned by varying the thiamine concentration (Fig. 3D). The PTIN system has a clear advantage of induction kinetics over the nmt1-based expression system as evidenced by the induction of half-maximal target protein levels $16.6 \mathrm{~h}, 19.3 \mathrm{~h}$, or $19.7 \mathrm{~h}$ earlier than the PREP3X, pREP41X, or pREP81X expression vectors, respectively (Fig. 3C). Induction by simple addition of thiamine to the medium is more convenient than the standard nmt1 promoter-driven overexpression system, which necessitates harvesting, washing, and resuspending cells in thiamine-free medium.

The pTIN system is modular, that is, the nmt1 promoter guides the expression of a repressive IncRNA that in turn controls the expression of the target gene. In principle, any one component may be changed to influence the expression level of the system; for example, the pTIN7m vector has a Pho7 binding site mutation in the tgp 1 promoter, the effect of which is to reduce basal expression in the absence of thiamine and dampen the extent of protein overproduction in the presence of thiamine. This variant has potential applications in cases where tighter repression is called for, for example, when working with endogenous or heterologous proteins that are toxic at high gene dosage (i.e., when expressed from multicopy fission yeast plasmids). Importing the pTIN system as a single integrated copy on the chromosome may also control gene dosage.

The pTIN system also has potential industrial applications. S. pombe has considerable advantages as a host for the industrial-scale production of eukaryotic proteins related to transactions conserved in higher eukarya (RNA splicing, RNA interference pathway, etc.) and advantages in glycosylation of proteins (Celik and Calik 2012; Gunduz Ergun et al. 2019). The pTIN system will allow convenient usage of a regulatable expression vector, where fermentation scale cultures may be grown in noninducing conditions and gene expression turned on by the addition of thiamine. The use of thiamine as an inducer has clear advantages due to its availability and low cost whereby $100 \mathrm{~g}$ of thiamine hydrochloride suffices for induction of 20,000 liters of fission yeast culture.

\section{MATERIALS AND METHODS}

\section{Generation of pTIN system vectors}

The thiamine-inducible vector (PTIN) consists of four elements in series from $5^{\prime}$ to $3^{\prime}$ (Fig. 1): (i) the nmt1 promoter, comprising a 1108-bp segment of genomic DNA consisting of nucleotides -1177 to -70 relative to the $+1 \mathrm{nmt} 1^{+}$translation start site; (ii) nc-tgp1 and the tgp1 promoter, a 1865-bp genomic DNA segment from the transcription start site of nc-tgp 1 IncRNA to the $-1 \mathrm{nt}$ relative to the $\operatorname{tgp} 1^{+}$translation start site; mutations of a cluster of DSR (determinant of selective removal) elements were included as shown in Figure 1; (iii) a poly-linker consisting of the restriction sites $5^{\prime}$-Notl, Pstl, Xhol, and Smal/Xmal; and (iv) a 647-bp segment of genomic DNA $3^{\prime}$ of the pho $1^{+}$stop codon consisting of poly(A) site(s) and a transcription terminator followed by an Spel restriction site. The Sacl-SphI LEU2-containing DNA fragment of pREP3X served as the plasmid backbone (Forsburg 1993). Two-stage overlap-extension PCR was used to fuse the $\mathrm{nmt} 1^{+}$promoter to the nc-tgp 1 transcription start site. To generate PTIN7m, the alternative expression vector with lower target gene expression, the Pho7 binding site of the PTIN vector was mutated from 5'-TCGGACATTCAA to 5'-TCAGACATTCAA (Fig. 1). A segment of genomic DNA starting at the +1 position of the pho1 open reading frame (ORF) to 647-bp $3^{\prime}$ of the pho $1^{+}$ stop codon that had the Notl and Spel sites upstream and downstream from this region, respectively, was cloned between the aforementioned sites in the PTIN or PTIN7m vectors. The fkh2 and sak1 ORFs were PCR amplified from S. pombe cDNA so as to introduce Notl and Xhol sites immediately upstream and downstream from the translation start and stop codon, respectively, and subsequently cloned in the PTIN vector using the aforementioned sites. The promoter-less PTIN-pho1 was generated by digesting the pTIN-pho1 vector with Nhel (restriction site $5^{\prime}$ of the nmt1 promoter; Fig. 1) and Notl, followed by fill-in of overhangs with DNA Polymerase I Klenow fragment (NEB) and bluntend ligation of the vector backbone. All plasmid constructs were sequenced to exclude unwanted mutations.

\section{Generation of the pREP series pho1 reporter constructs}

The pho1 ORF was PCR amplified from S. pombe genomic DNA so as to introduce Xhol and Xmal sites immediately upstream and downstream from the translation start and stop codon, respectively, and subsequently cloned in PREP3X, PREP41X, or pREP81X vectors (Forsburg 1993) using the aforementioned sites. All plasmid constructs were sequenced to exclude unwanted mutations.

\section{Deletion of pho4 in [prt2-pho84-prt-pho1] $\Delta$ cells}

pho4 DNA segments [ -452 to -1 and +1845 to +2315 relative to the pho $4^{+}$translational start codon $\left.(+1)\right]$, were PCR amplified and cloned upstream and downstream, respectively, of the natMX antibiotic resistance cassette in a bacterial plasmid. The linear pho4::natMX gene disruption cassette was excised from the plasmid and transfected into haploid S. pombe [prt2-pho84-prtpho1] $\Delta$ cells (Garg et al. 2018b). Nourseothricin-resistant transformants were selected and analyzed by Southern blotting to confirm correct integration at the pho4 locus.

\section{Plasmid transformation}

Plasmids were transfected as specified by the lithium acetate method (Forsburg and Rhind 2006) into WT (leu1-32 ura4-D18 ade6-M216 his3-D1) or pho4s pho1s (pho4::natMX [prt2pho84-prt-pho1]::hygMX leu1-32 ura4-D18 ade6[M210 or M216] his3-D1) cells cultured in thiamine-free PMG (pombe minimal glutamate) medium, pH 5.6, supplemented with $250 \mathrm{mg} / \mathrm{L}$ each of adenine, uracil, leucine, histidine, and lysine. Note that the plasmids must be transfected in cells cultivated in thiamine- 
free medium to prevent any de-repression of the target gene post-transformation due to residual intracellular thiamine. Transformants were selected on Leu- PMG agar medium at $30^{\circ} \mathrm{C}$.

\section{Acid phosphatase activity assay}

Aliquots of exponentially growing cultures were harvested, washed with water, and resuspended in water. To quantify acid phosphatase activity, reaction mixtures $(200 \mu \mathrm{L})$ containing 100 $\mathrm{mM}$ sodium acetate ( $\mathrm{pH} 4.2), 10 \mathrm{mM}$ p-nitrophenyl phosphate (NEB), and cells (ranging from 0.001 to $0.1 \mathrm{~A}_{600}$ units) were incubated for $5 \mathrm{~min}$ at $30^{\circ} \mathrm{C}$. The reactions were quenched by addition of $1 \mathrm{~mL}$ of $1 \mathrm{M}$ sodium carbonate; the cells were removed by centrifugation and the absorbance of the supernatant was measured at $410 \mathrm{~nm}$. Acid phosphatase activity is expressed as the ratio of $A_{410}$ ( $p$-nitrophenol production) to $A_{600}$ (cells). The data are averages ( \pm SEM) of at least three assays using cells from three independent cultures.

\section{RNA analysis}

Total RNA was extracted via the hot phenol method (Köhrer and Domdey 1991) from three $A_{600}$ units of harvested yeast cells. For analysis of specific transcripts by primer extension, aliquots $(5 \mu \mathrm{g})$ of total RNA were templated for M-MuLV reverse transcriptasecatalyzed extensions of $5^{\prime}{ }^{32} \mathrm{P}$-labeled oligodeoxynucleotide primers complementary to the pho 1 and act 1 mRNAs in one reaction mix. The primer sequence for act 1 was $5^{\prime}$-GATTTCTTCTTCC ATGGTCTTGTC, and for pho1, 5'-GTTGGCACAAACGACG GCC. The primer extension reactions were performed as described previously (Schwer et al. 1998), and the products were analyzed by electrophoresis of the reaction mixtures through a $22-\mathrm{cm} 8 \%$ polyacrylamide gel containing $7 \mathrm{M}$ urea in $80 \mathrm{mM}$ Tris-borate, $1.2 \mathrm{mM}$ EDTA. The ${ }^{32} \mathrm{P}$-labeled primer extension products were visualized by autoradiography of the dried gel. Quantification of pho1 and act1 mRNA levels was done by scanning the dried gel with a phosphorimager and analyzing the data in ImageQuant software.

\section{Fluorescence microscopy}

Aliquots of cultured cells were fixed in $70 \%$ ethanol as described in the text. Fixed cells were harvested, washed twice with water, and resuspended in water. Equal volumes of the cell suspension and mounting solution [75 $\mu \mathrm{g} / \mathrm{mL}$ DAPI (4',6-diamidino-2-phenylindole dihydrochloride; Sigma 32670); $4.6 \mathrm{mg} / \mathrm{mL}$ Calcofluor White (Sigma F3543) in mounting medium (Vectashield $\mathrm{H}$ 1000)] were mixed and incubated for $5 \mathrm{~min}$ followed by slide preparation. Cells were observed by fluorescent microscopy and 30-60 independent successive frames were imaged and subsequently counted in Image J.

\section{DATA DEPOSITION}

The DNA sequence of the PTIN plasmid utilized in this publication has been deposited in NCBI's GenBank database and is accessible through GenBank accession number MT740318 (https://www.ncbi.nlm.nih.gov/nuccore/MT740318).

\section{ACKNOWLEDGMENTS}

I thank Dr. Stewart Shuman (S.S.) and Dr. Beate Schwer (B.S.) for valuable suggestions and support over the course of the study and critical reading of the manuscript. All work was conducted in the laboratories of Drs. S. Shuman and B. Schwer. I thank Ana

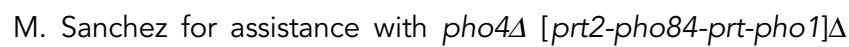
strain construction. This work was supported by National Institute of General Medical Sciences (grant number R01GM52470 to S.S. and B.S., R35-GM126945 to S.S.).

Received April 20, 2020; accepted August 7, 2020.

\section{REFERENCES}

Ard R, Tong P, Allshire RC. 2014. Long non-coding RNA-mediated transcriptional interference of a permease gene confers drug tolerance in fission yeast. Nat Commun 5: 5576. doi:10.1038/ ncomms6576

Basi G, Schmid E, Maundrell K. 1993. TATA box mutations in the Schizosaccharomyces pombe nmt1 promoter affect transcription efficiency but not the transcription start point or thiamine repressibility. Gene 123: 131-136. doi:10.1016/0378-1119(93)90552-E

Bellemare DR, Sanschagrin M, Beaudoin J, Labbe S. 2001. A novel copper-regulated promoter system for expression of heterologous proteins in Schizosaccharomyces pombe. Gene 273: 191-198. doi:10.1016/S0378-1119(01)00591-1

Buck V, Ng SS, Ruiz-Garcia AB, Papadopoulou K, Bhatti S, Samuel JM, Anderson M, Millar JB, Mclnerny CJ. 2004. Fkh2p and Sep1p regulate mitotic gene transcription in fission yeast. J Cell Sci 117: 5623-5632. doi:10.1242/jcs.01473

Carter-O'Connell I, Peel MT, Wykoff DD, O'Shea EK. 2012. Genomewide characterization of the phosphate starvation response in Schizosaccharomyces pombe. BMC Genomics 13: 697. doi:10 .1186/1471-2164-13-697

Celik E, Calik P. 2012. Production of recombinant proteins by yeast cells. Biotechnol Adv 30: 1108-1118. doi:10.1016/j.biotechadv .2011.09.011

Chatterjee D, Sanchez AM, Goldgur Y, Shuman S, Schwer B. 2016. Transcription of IncRNA prt, clustered prt RNA sites for Mmi1 binding, and RNA polymerase II CTD phospho-sites govern the repression of pho1 gene expression under phosphate-replete conditions in fission yeast. RNA 22: 1011-1025. doi:10.1261/rna.056515.116

Chen D, Toone WM, Mata J, Lyne R, Burns G, Kivinen K, Brazma A, Jones N, Bahler J. 2003. Global transcriptional responses of fission yeast to environmental stress. Mol Biol Cell 14: 214-229. doi:10 .1091/mbc.e02-08-0499

Chen HM, Futcher B, Leatherwood J. 2011. The fission yeast RNA binding protein $\mathrm{Mmi1}$ regulates meiotic genes by controlling intron specific splicing and polyadenylation coupled RNA turnover. PLoS One 6: e26804. doi:10.1371/journal.pone.0026804

Faryar K, Gatz C. 1992. Construction of a tetracycline-inducible promoter in Schizosaccharomyces pombe. Curr Genet 21: 345-349. doi:10.1007/BF00351693

Forsburg SL. 1993. Comparison of Schizosaccharomyces pombe expression systems. Nucleic Acids Res 21: 2955-2956. doi:10 .1093/nar/21.12.2955

Forsburg SL, Rhind N. 2006. Basic methods for fission yeast. Yeast 23: 173-183. doi:10.1002/yea.1347

Fujita Y, Tohda H, Giga-Hama Y, Takegawa K. 2006. Heat shock-inducible expression vectors for use in Schizosaccharomyces pombe. FEMS Yeast Res 6: 883-887. doi:10.1111/j.1567-1364 .2006.00093.x 
Garg A, Futcher B, Leatherwood J. 2015. A new transcription factor for mitosis: in Schizosaccharomyces pombe, the RFX transcription factor Sak1 works with forkhead factors to regulate mitotic expression. Nucleic Acids Res 43: 6874-6888. doi:10.1093/nar/gkv274

Garg A, Goldgur Y, Schwer B, Shuman S. 2018a. Distinctive structural basis for DNA recognition by the fission yeast $\mathrm{Zn}_{2} \mathrm{Cys}_{6}$ transcription factor Pho7 and its role in phosphate homeostasis. Nucleic Acids Res 46: 11262-11273. doi:10.1093/nar/gkx957

Garg A, Sanchez AM, Shuman S, Schwer B. 2018b. A long noncoding (Inc)RNA governs expression of the phosphate transporter Pho84 in fission yeast and has cascading effects on the flanking prt IncRNA and pho1 genes. J Biol Chem 293: 4456-4467. doi:10 .1074/jbc.RA117.001352

Garg A, GoldgurY, Sanchez AM, Schwer B, Shuman S. 2019. Structure of fission yeast transcription factor $\mathrm{Pho7}$ bound to pho1 promoter DNA and effect of Pho7 mutations on DNA binding and phosphate homeostasis. Mol Cell Biol 39: e00132-00119. doi:10 .1128/MCB.00132-19

Gunduz Ergun B, Huccetogullari D, Ozturk S, Celik E, Calik P. 2019. Established and upcoming yeast expression systems. Methods Mol Biol 1923: 1-74. doi:10.1007/978-1-4939-9024-5_1

Harigaya $Y$, Tanaka H, Yamanaka S, Tanaka K, Watanabe $Y$, Tsutsumi C, Chikashige Y, Hiraoka Y, Yamashita A, Yamamoto M. 2006. Selective elimination of messenger RNA prevents an incidence of untimely meiosis. Nature 442: 45-50. doi:10 $.1038 /$ nature04881

Hayles J, Nurse P. 2018. Introduction to fission yeast as a model system. Cold Spring Harb Protoc 2018. doi:10.1101/pdb.top079749

Hennig S, Hornauer N, Rodel G, Ostermann K. 2018. Pheromone-inducible expression vectors for fission yeast Schizosaccharomyces pombe. Plasmid 95: 1-6. doi:10.1016/j.plasmid.2017.11.002

Hoffman CS, Winston F. 1989. A transcriptionally regulated expression vector for the fission yeast Schizosaccharomyces pombe. Gene 84: 473-479. doi:10.1016/0378-1119(89)90523-4

Hoffman CS, Wood V, Fantes PA. 2015. An ancient yeast for young geneticists: a primer on the Schizosaccharomyces pombe model system. Genetics 201: 403-423. doi:10.1534/genetics.115.181503

lacovoni JS, Russell P, Gaits F. 1999. A new inducible protein expression system in fission yeast based on the glucose-repressed inv1 promoter. Gene 232: 53-58. doi:10.1016/S0378-1119(99) 00116-X

Javerzat JP, Cranston G, Allshire RC. 1996. Fission yeast genes which disrupt mitotic chromosome segregation when overexpressed. Nucleic Acids Res 24: 4676-4683. doi:10.1093/nar/24.23.4676

Kilchert C, Wittmann S, Passoni M, Shah S, Granneman S, Vasiljeva L. 2015. Regulation of mRNA levels by decay-promoting introns that recruit the exosome specificity factor Mmi1. Cell Rep 13: 2504 2515. doi:10.1016/j.celrep.2015.11.026

Köhrer K, Domdey H. 1991. Preparation of high molecular weight RNA. Methods Enzymol 194: 298-405. doi:10.1016/0076-6879 (91)94030-G

Lee NN, Chalamcharla VR, Reyes-Turcu F, Mehta S, Zofall M, Balachandran V, Dhakshnamoorthy J, Taneja N, Yamanaka S, Zhou $\mathrm{M}$, et al. 2013. Mtr4-like protein coordinates nuclear RNA processing for heterochromatin assembly and for telomere maintenance. Cell 155: 1061-1074. doi:10.1016/j.cell.2013.10.027

Marguerat S, Schmidt A, Codlin S, Chen W, Aebersold R, Bahler J. 2012. Quantitative analysis of fission yeast transcriptomes and pro- teomes in proliferating and quiescent cells. Cell 151: 671-683. doi:10.1016/j.cell.2012.09.019

Matsuzawa T, Tohda H, Takegawa K. 2013. Ethanol-inducible gene expression using gld1 (+) promoter in the fission yeast Schizosaccharomyces pombe. Appl Microbiol Biotechnol 97: 6835-6843. doi:10.1007/s00253-013-4812-2

Maundrell K. 1990. nmt1 of fission yeast. A highly transcribed gene completely repressed by thiamine. J Biol Chem 265: 1085710864.

Ohira MJ, Hendrickson DG, Scott Mclsaac R, Rhind N. 2017. An estradiol-inducible promoter enables fast, graduated control of gene expression in fission yeast. Yeast 34: 323-334. doi:10.1002/yea .3235

Rustici G, van Bakel H, Lackner DH, Holstege FC, Wijmenga C, Bahler J, Brazma A. 2007. Global transcriptional responses of fission and budding yeast to changes in copper and iron levels: a comparative study. Genome Biol 8: R73. doi:10.1186/gb-2007$8-5-r 73$

Sanchez AM, Shuman S, Schwer B. 2018. Poly(A) site choice and Pol2 CTD Serine- 5 status govern IncRNA control of phosphate-responsive tgp1 gene expression in fission yeast. RNA 24: 237-250. doi:10.1261/rna.063966.117

Schwer B, Mao X, Shuman S. 1998. Accelerated mRNA decay in conditional mutants of yeast mRNA capping enzyme. Nucleic Acids Res 26: 2050-2057. doi:10.1093/nar/26.9.2050

Schwer B, Sanchez AM, Shuman S. 2015. RNA polymerase II CTD phospho-sites Ser5 and Ser7 govern phosphate homeostasis in fission yeast. RNA 21: 1770-1780. doi:10.1261/rna.052555.115

Schwer B, Sanchez AM, Garg A, Chatterjee D, Shuman S. 2017. Defining the DNA binding site recognized by the fission yeast $\mathrm{Zn}_{2} \mathrm{Cys}_{6}$ transcription factor $\mathrm{Pho} 7$ and its role in phosphate homeostasis. MBio 8: e01218-01217. doi:10.1128/ mBio.01218-17

Shah S, Wittmann S, Kilchert C, Vasiljeva L. 2014. IncRNA recruits RNAi and the exosome to dynamically regulate pho1 expression in response to phosphate levels in fission yeast. Genes Dev 28: 231-244. doi:10.1101/gad.230177.113

Vachon L, Wood J, Kwon EJ, Laderoute A, Chatfield-Reed K, Karagiannis J, Chua G. 2013. Functional characterization of fission yeast transcription factors by overexpression analysis. Genetics 194: 873-884. doi:10.1534/genetics.113.150870

Vassiliadis D, Wong KH, Andrianopoulos A, Monahan BJ. 2019. A genome-wide analysis of carbon catabolite repression in Schizosaccharomyces pombe. BMC Genomics 20: 251. doi:10 .1186/s12864-019-5602-8

Watson AT, Werler P, Carr AM. 2011. Regulation of gene expression at the fission yeast Schizosaccharomyces pombe urg1 locus. Gene 484: 75-85. doi:10.1016/j.gene.2011.05.028

Watt S, Mata J, Lopez-Maury L, Marguerat S, Burns G, Bahler J. 2008. urg1: a uracil-regulatable promoter system for fission yeast with short induction and repression times. PLoS One 3: e1428. doi:10 .1371/journal.pone.0001428

Yamashita A, Shichino $Y$, Tanaka H, Hiriart E, Touat-Todeschini L, Vavasseur A, Ding DQ, Hiraoka Y, Verdel A, Yamamoto M. 2012. Hexanucleotide motifs mediate recruitment of the RNA elimination machinery to silent meiotic genes. Open Biol 2: 120014. doi:10.1098/rsob.120014 

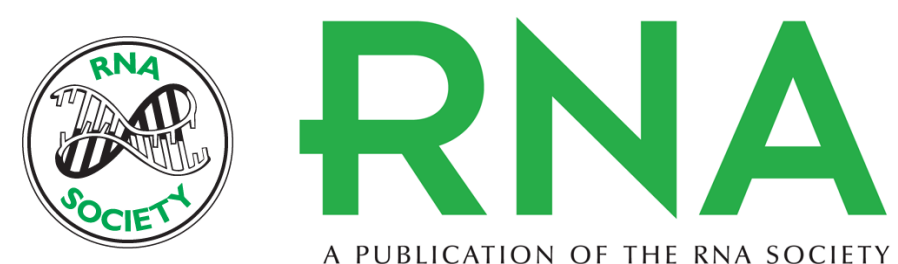

A PUBLICATION OF THE RNA SOCIETY

\title{
A IncRNA-regulated gene expression system with rapid induction kinetics in the fission yeast Schizosaccharomyces pombe
}

\author{
Angad Garg
}

RNA 2020 26: 1743-1752 originally published online August 11, 2020

Access the most recent version at doi:10.1261/rna.076000.120

\begin{abstract}
References This article cites 43 articles, 12 of which can be accessed free at: http://rnajournal.cshlp.org/content/26/11/1743.full.html\#ref-list-1

Creative This article is distributed exclusively by the RNA Society for the first 12 months after the Commons License full-issue publication date (see http://rnajournal.cshlp.org/site/misc/terms.xhtml). After 12 months, it is available under a Creative Commons License (Attribution-NonCommercial 4.0 International), as described at http://creativecommons.org/licenses/by-nc/4.0/.
\end{abstract}

Email Alerting Receive free email alerts when new articles cite this article - sign up in the box at the Service top right corner of the article or click here.

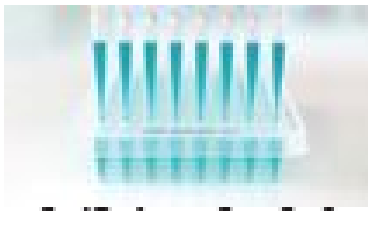

\section{Providing Precise Solutions for} your research.

To subscribe to $R N A$ go to:

http://rnajournal.cshlp.org/subscriptions 